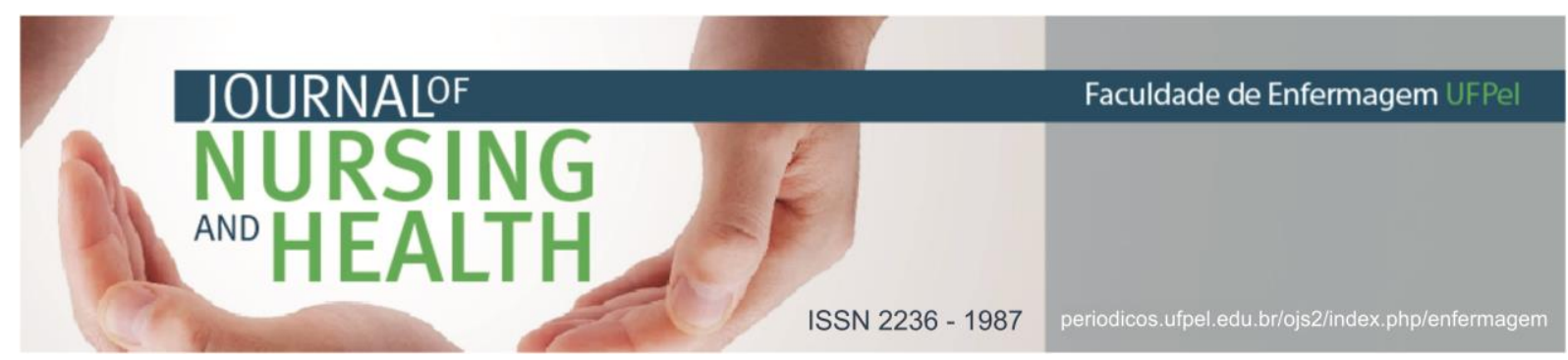

ARTIGO ORIGINAL

\title{
Análise de determinantes intrapessoais e interpessoais como motivos de recaída no contexto da dependência química
}

\author{
Analysis of intrapersonal and interpersonal determinants as reasons for relapse in \\ the chemical dependence
}

\section{Análisis de determinantes intrapersonales e interpersonales como razones de recaídas en la dependencia química}

Buriola, Aline Aparecida ${ }^{1}$; Silva, Amanda Stefani Torquato da ${ }^{2}$; Prestes, Anny Helisy Occhi ${ }^{3}$; Nascimento, Lorrayne Andressa dos Santos; Cavalleri, Matheus Zanelato ${ }^{5}$; Bordão, Murilo Henrique

Fernandes Costa Colette ${ }^{6}$

Como citar este artigo: Buriola AA; Silva AST; Prestes AHO; Nascimento LAS; Cavalleri MZ; Bordão MHFCC. Análise de determinantes intrapessoais e interpessoais como motivos de recaída no contexto da dependencia química. J. nurs. health. 2018;8(2):e188209

\section{RESUMO}

Objetivo: identificar os motivos de recaída de dependentes químicos, em tratamento em um Centro de Atenção Psicossocial para álcool e drogas. Método: pesquisa descritiva e exploratória, com abordagem qualitativa. Os dados foram coletados por meio de entrevista semiestruturada, com 15 pessoas em tratamento ativo para dependência química. Os dados foram tratados por meio da análise de conteúdo. Resultados: dentre os determinantes interpessoais identificados, destacam-se o apoio familiar, o grupo de convívio social, a moradia fixa, e também o vínculo empregatício. Em geral, o ambiente externo adequado minimiza a probabilidade de reuso. Em relação aos intrapessoais, são recorrentes a fissura, a dependência psíquica e a capacidade de lidar com frustrações. Conclusão: acredita-se que para evitar uma recaída, o dependente químico em tratamento, necessita de uma internação domiciliar, assim quando os determinantes interpessoais e intrapessoais ocorrerem, o paciente estará assistido, com menor risco de relapso.

Descritores: Drogas ilícitas; Terapêutica; Fatores de risco; Recidiva

1 Enfermeira. Doutora em Enfermagem. Universidade do Oeste Paulista (UNOESTE). aliburiola@gmail.com http://orcid.org/0000-0003-1232-6115

2 Enfermeira. Especialista em Qualidade e Segurança do Paciente. Universidade do Oeste Paulista (UNOESTE). amandastefani_torquato@hotmail.com. http://orcid.org/0000-0002-8049-5415

3 Acadêmica de Medicina. Universidade do Oeste Paulista (UNOESTE). annyhelisy@live.com http://orcid.org/0000-0002-5080-7430

4 Enfermeira. Mestranda em Educação. Universidade do Oeste Paulista (UNOESTE). lo_capv@hotmail.com https: / / orcid.org/0000-0001-5392-0802

5 Acadêmico de Medicina. Universidade do Oeste Paulista (UNOESTE). mzcavalleri@gmail.com. http://orcid.org/0000-0003-1621-1307

6 Acadêmico de Medicina. Universidade do Oeste Paulista (UNOESTE). murilobordao@hotmail.com http://orcid.org/0000-0001-5693-5778 


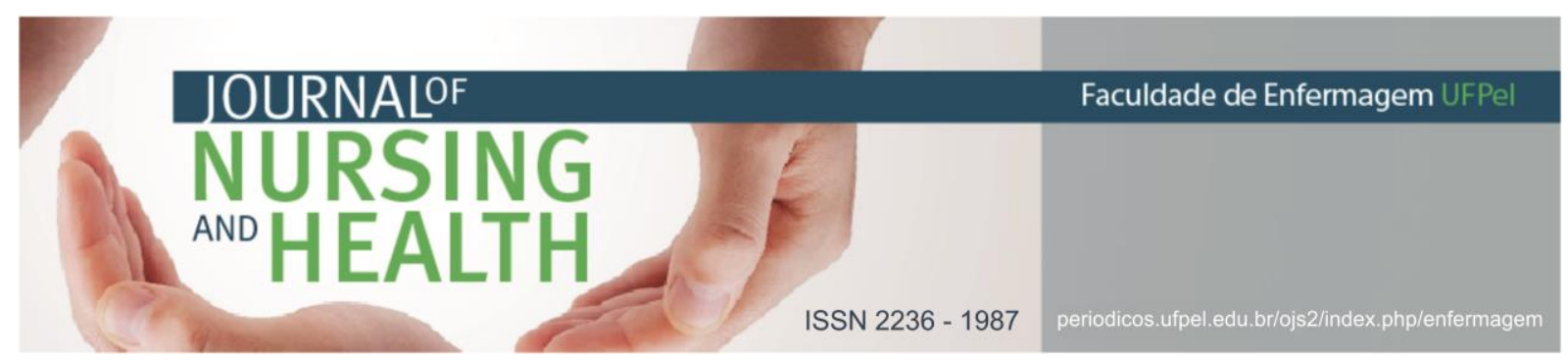

ABSTRACT

Objective: this study aimed to identify the relapse reasons of drug addicts in treatment in a Psychosocial Care Center - alcohol and drugs. Method: a descriptive and exploratory research with a qualitative approach was carried out. Data were collected through semi-structured interviews with 15 people in active treatment for chemical dependency, and they are analyzed by content analysis. Results: the main interpersonal determinants perceived by drug addicts as causes of relapse were family support, social circle, fixed residence and job opportunity. Generally, the adequate external environment decreases the probability of a relapse. When regarding the intrapersonal determinants, fissure, psychological dependency and resilience are the most recurring. Conclusion: it is believed that, prevent a relapse, the addict in treatment, needs home care, therefore, when both interpersonal and intrapersonal determinants appear, the patient will be assisted, with minor chances of relapse.

Descriptors: Street drugs; Therapeutics; Risk factors; Recurrence

\section{RESUMEN}

Objetivo: identificar la motivación de recaídas del dependiente químico en el tratamiento en un Centro de Atención Psicosocial - alcohol y drogas. Método: pesquisa descriptiva y exploratoria, con el abordaje cualitativo. Los datos fueron colectados por medio de entrevistas semiestructuradas, con 15 personas en el tratamiento activo para la dependencia química. Los datos fueron tratados por análisis del contenido. Resultados: los determinantes interpersonales destacados como causas de recaídas fueran el apoyo familiar, el círculo social, la morada y trabajo. En general, el ambiente externo adecuado minimiza las chances de recurrencia del uso de las drogas. En relación con los intrapersonales, son recurrentes la fisura, la dependencia psíquica y la capacidad para tratar con la frustración. Conclusión: se hace creer que, para evitar una recaída, el dependiente químico en tratamiento, necesita de una internación hogareña, así cuando los determinantes interpersonales $e$ intrapersonal surgen, el paciente estará asistido, con menor posibilidad de recaída.

Descriptores: Drogas ilícitas; Terapéutica; Factores de riesgo; Recurrencia

\section{INTRODUÇÃO}

Dependência química é definida como uma doença multicausal, que necessita de tratamento clínico, farmacológico e de abordagem psicossocial, que englobe as necessidades de saúde do usuário e de sua família. ${ }^{1} 0$ Diagnostic and Statistical Manual of Mental Disorders (DSM-5) categoriza dependência química como uma doença crônica e recorrente, com presença de transtornos por uso de substâncias, sendo notável a complexidade da patologia, uma vez que esta engloba características físicas mentais e sociais, de forma a também constituir um problema de saúde pública. ${ }^{2}$
Segundo a Organização Mundial da Saúde (OMS), estima-se que cerca de $10 \%$ da população mundial, que vive nos grandes centros urbanos, abusam de algum tipo de substância psicoativa. ${ }^{3} 0$ quadro atual do Brasil se assemelha a esse panorama, sendo apontado no Relatório Mundial sobre Drogas da Organização das Nações Unidas, que cerca de 29,5 milhões de pessoas da população adulta mundial usam drogas de forma problemática, com isto vem despertando uma forte preocupação social. ${ }^{3}$

No uso de substâncias psicoativas, evidencia-se inúmeras consequências e prejuízos, muitas vezes irreversíveis 


\section{JOURNALOF \\ NURSING \\ ANO HEALTH}

ISSN 2236 - 198

de enfrentamento vinculada ao tratamento. ${ }^{8}$

Determinantes interpessoais são influências marcadas pelo contexto a qual indivíduo está inserido, seja em seu âmbito familiar, afetivo ou social. ${ }^{10}$ Ter a capacidade de identificar esses fatores de risco, e compreender sua inabilidade em lidar com os mesmos, poderá melhorar suas habilidades e estratégias no enfrentamento e/ou antecipação de comportamentos de recaída. ${ }^{5}$

Determinantes intrapessoais são aqueles que se relacionam com as expectativas de resultados, à auto eficácia, enfrentamento, motivação, fissura e estados emocionais. Faz-se necessário ressaltar que tantos os determinantes interpessoais quanto os intrapessoais, por vezes, associam-se uns com os outros no contexto do processo de recaída de dependentes químicos. ${ }^{9}$

Sendo assim, de acordo com as informações apresentadas surge a seguinte questão de pesquisa: Quais os motivos que levam dependentes químicos a terem momentos de recaídas durante o tratamento? Para responder a esta questão tem-se como objetivo identificar os motivos de recaída de dependentes químicos, em tratamento em um Centro de Atenção Psicossocial para álcool e drogas.

\section{MÉTODO}

Foi realizado um estudo descritivo e exploratório, com abordagem qualitativa, que pode ser entendida como "aquela capaz de incorporar a questão do significado e da intencionalidade inerentes aos atos, 


\section{IOURNAIOF

às relações e às estruturas sociais, sendo essas últimas tomadas tanto no seu advento quanto na sua transformação como construções humanas significativas". 10:622.

Os dados foram coletados nos meses de junho e julho de 2015 , junto a 15 indivíduos em acompanhamento para dependência química, em um Centro de Atenção Psicossocial álcool e drogas (CAPS-ad), localizado no Oeste Paulista. Como critérios de inclusão foram eleitas àquelas pessoas que estavam em acompanhamento no CAPS-ad há no mínimo um mês e que possuíssem histórico de recaídas no último ano. Para que o indivíduo já se sentisse pertencente ao grupo e com um vínculo minimamente estruturado, foi necessário que o prazo mínimo de um mês em tratamento no CAPS-ad fosse estipulado, a fim de que barreiras como o vínculo e a confiança fossem ultrapassadas com sucesso.

Ainda neste sentido, o critério de histórico de recaídas se fez necessário para que os indivíduos participantes do presente estudo pudessem relatar sobre algo do qual já vivenciou, bem como quais foram suas experiências, sentimentos e fatores desencadeantes de tal situação, para que pudessem colaborar e se enquadrar de forma efetiva na temática principal desta pesquisa. Sendo assim, foram excluídos do estudo aquelas pessoas em tratamento no CAPS-ad que não apresentavam histórico de recaídas ou estavam em tratamento há menos de um mês.

A coleta dos dados foi realizada
por meio de entrevista
semiestruturada, em sala de consulta
de enfermagem previamente agendada

no CAPS-ad, sendo as mesmas gravadas em dois gravadores digitais. Para a entrevista foi utilizado um roteiro constituído pelas seguintes questões: conte detalhadamente como foi 0 momento da sua recaída, aponte os motivos que te levaram a reiniciar o uso de substâncias psicoativas. A fim de contribuir na análise e interpretação dos dados e para caracterizar os participantes da pesquisa também foram coletados dados como: sexo, idade, escolaridade, profissão, tempo de acompanhamento no CAPS-ad e número de recaídas.

Para a análise, as entrevistas foram transcritas na íntegra e submetidas à análise de conteúdo temática. $\mathrm{Na}$ pré-análise, fase de organização dos documentos, ocorreram três leituras flutuantes que tinham como propósito a escolha dos relatos, formulação de hipóteses, a escolha dos índices de análise e elaboração de indicadores categóricos para fundamentar a interpretação dos dados; a fase de exploração do material consistiu em quatro leituras sistematizadas que tinham como intencionalidade fazer agrupamentos e associações que respondessem aos objetivos do estudo e assim construir as categorias analíticas. Por fim, a fase de tratamento dos resultados compreendeu o momento em que foram realizadas as inferências e a interpretação dos resultados encontrados discutindo-os com base na literatura. ${ }^{11}$

Este estudo obedeceu às
diretrizes estabelecidas pela
Resolução $466 / 12$ do Conselho
Nacional de Saúde, e foi aprovado pelo


Comitê de Ética em Pesquisa envolvendo Seres Humanos da Universidade do Oeste Paulista com Parecer $n^{\circ} 2733$ e protocolo Certificado de Apresentação para Apreciação Ética (CAAE) $\quad \mathrm{n}^{\circ} \quad 43384715.2 .0000 .5515$. Todos os participantes assinaram o Termo de Consentimento Livre e Esclarecido em duas vias, e para garantir 0 anonimato dos participantes, os trechos/excertos dos depoimentos foram acompanhados pela sigla "E", seguida de um número arábico correspondente à sequência da entrevista.
ISSN 2236 - 1987

\section{RESULTADOS}

Foram entrevistadas 15 pessoas em tratamento para dependência química, sendo que quatro pertenciam ao sexo feminino e 11 ao sexo masculino. A idade variou entre 20 e 66 anos. Nove possuíam ensino fundamental incompleto, apenas um concluiu o ensino médio e um referiu ser analfabeto. A média de tempo de tratamento no CAPS foi de um ano e seis meses. A seguir, na figura 1 e na figura 2 estão descritas as categorias analíticas de acordo com os quadros dos dados encontrados.

Figura 1: Primeira categoria - determinantes interpessoais percebidos pelos dependentes químicos como causa de suas recaídas.

\begin{tabular}{|c|c|c|}
\hline CATEGORIA & \multicolumn{2}{|c|}{$\begin{array}{c}\text { DETERMINANTES INTERPESSOAIS PERCEBIDOS PELOS DEPENDENTES } \\
\text { QUÍMICOS COMO CAUSA DE SUAS RECAIIDAS }\end{array}$} \\
\hline ENTREVISTADOS & DISCURSO & $\begin{array}{c}\text { PRINCIPAL } \\
\text { MOTIVO DE } \\
\text { RECAÍDA }\end{array}$ \\
\hline $\begin{array}{l}\text { E4, masculino, } \\
\text { segundo grau } \\
\text { completo, } \\
\text { desempregado, } \\
\text { atualmente utiliza } \\
\text { álcool e já usou } \\
\text { maconha, cocaína e } \\
\text { crack, um ano de } \\
\text { tratamento, com três } \\
\text { recaídas. }\end{array}$ & $\begin{array}{l}\text { "Durante o tempo de tratamento eu fui morar em } \\
\text { diversas casas de colegas e, às vezes, nessas casas as } \\
\text { pessoas tinham uma relação forte com drogas e } \\
\text { bebida [...] e nesse meio a gente acaba encontrando } \\
\text { uma pessoa lá, que te chama para fumar um } \\
\text { baseado, daí é onde você acaba começando tudo } \\
\text { novamente" }\end{array}$ & $\begin{array}{l}\text { Influência sofrida } \\
\text { por amigos. } \\
\text { Coesão do } \\
\text { ambiente familiar. }\end{array}$ \\
\hline 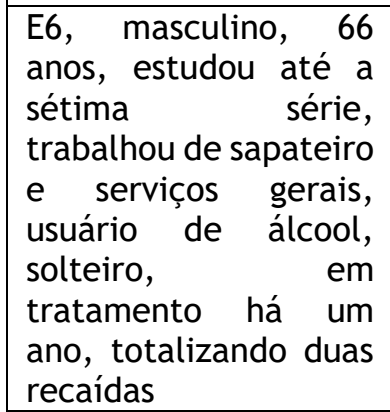 & $\begin{array}{l}\text { "O perigo para mim são os colegas de bar, os falsos } \\
\text { amigos de bar, porque eles incentivam a tomar um } \\
\text { gole e quando você vê já está bebendo muito." } \\
\text { "Agora uma sobrinha minha há um tempo em um } \\
\text { almoço na casa dela, ela falou "bebe tio", aí eu } \\
\text { tomei umas duas, três latinhas, almocei e fui } \\
\text { embora, mas daí nessa ocasião eu voltei a beber } \\
\text { muito, inclusive bebendo junto com os parentes." }\end{array}$ & $\begin{array}{l}\text { Pressão socia } \\
\text { imposta por } \\
\text { amigos } \\
\text { conhecidos que } \\
\text { também utilizam } \\
\text { substâncias } \\
\text { psicoativas. } \\
\text { Quebra do vínculc } \\
\text { familiar. }\end{array}$ \\
\hline
\end{tabular}




\begin{tabular}{|c|c|c|}
\hline $\begin{array}{l}\text { E8, masculino, } 51 \\
\text { anos, sem } \\
\text { escolaridade, } \\
\text { operador de máquinas } \\
\text { agrícolas, usuário de } \\
\text { álcool, solteiro, um } \\
\text { ano de tratamento, } \\
\text { contabilizando quatro } \\
\text { recaídas. }\end{array}$ & $\begin{array}{l}\text { "Ah o que me faz recair sempre são os amigos da rua } \\
\text { que a gente encontra um, encontra outro e fala "ah } \\
\text { vamos toma uma", daí você toma né." }\end{array}$ & $\begin{array}{lr}\text { Frequência } & \text { a } \\
\text { lugares } & \text { que } \\
\text { facilitam } & \text { a } \\
\text { aquisição } & \text { e } \\
\text { contato próximo } \\
\text { com a droga. }\end{array}$ \\
\hline $\begin{array}{l}\text { E10, masculino, } 47 \\
\text { anos, escolaridade até } \\
\text { a quinta série, } \\
\text { tratorista, usuário de } \\
\text { álcool, divorciado, em } \\
\text { tratamento há } \\
\text { aproximadamente } 5 \\
\text { meses, somente uma } \\
\text { recaída. }\end{array}$ & $\begin{array}{l}\text { "Eu sou de uma família toda alcoólatra, então } \\
\text { quando a gente se junta é difícil não voltar a beber, } \\
\text { é nesse caso que a gente acaba recaindo, porque na } \\
\text { minha família a bebida rega a mesa." }\end{array}$ & $\begin{array}{l}\text { Comportamento } \\
\text { cultural } \\
\text { (Confraternizações } \\
\text { familiares). }\end{array}$ \\
\hline $\begin{array}{l}\text { E1, masculino, } 34 \\
\text { anos, quinta série, } \\
\text { usuário de crack e } \\
\text { álcool, solteiro, em } \\
\text { tratamento há } \\
\text { aproximadamente } 4 \\
\text { meses, não soube } \\
\text { dizer quantas recaídas } \\
\text { teve. }\end{array}$ & $\begin{array}{l}\text { "Se briga com alguém eu acabo recaindo [...]. } \\
\text { Quando eu discuto com o meu irmáozinho, aí dá } \\
\text { vontade de usar a droga. Também quando perdi } \\
\text { minha namorada, aí que eu embalei mesmo, já que } \\
\text { ela não quer mais, eu vou continuar a usar drogas." }\end{array}$ & Conflitos sociais. \\
\hline $\begin{array}{l}\text { E13, masculino, } 60 \\
\text { anos, sétima série } \\
\text { incompleta, } \\
\text { topógrafo, faz uso de } \\
\text { álcool, viúvo, em } \\
\text { tratamento há } \\
\text { aproximadamente um } \\
\text { ano, uma recaída. }\end{array}$ & $\begin{array}{l}\text { "Ah, às vezes não consegue um emprego, é difícil } \\
\text { emprego, daí a gente desanima e busca a droga." }\end{array}$ & $\begin{array}{l}\text { Situação } \\
\text { empregatícia. }\end{array}$ \\
\hline
\end{tabular}

Figura 2: Segunda categoria - Determinantes intrapessoais percebidos pelos dependentes químicos como causa de suas recaídas

\begin{tabular}{|c|c|c|}
\hline CATEGORIA & \multicolumn{2}{|c|}{$\begin{array}{c}\text { DETERMINANTES INTRAPESSOAIS PERCEBIDOS PELOS DEPENDENTES } \\
\text { QUÍMICOS COMO CAUSA DE SUAS RECAÍDAS }\end{array}$} \\
\hline ENTREVISTADOS & DISCURSO & $\begin{array}{c}\text { PRINCIPAL } \\
\text { MOTIVO DE } \\
\text { RECAÍDA }\end{array}$ \\
\hline $\begin{array}{l}\text { E2, masculino, } 29 \text { anos, } \\
\text { segundo grau incompleto, } \\
\text { usuário de crack, } \\
\text { solteiro, em tratamento } \\
\text { há quatro anos, com } \\
\text { inúmeras recaídas. }\end{array}$ & $\begin{array}{l}\text { "Não tem como eu falar o que me levou a ter recaído } \\
{[\ldots] \text { Eu mesmo fui, porque eu gosto [...], ainda não }} \\
\text { sei me controlar quando bate aquela vontade eu volto } \\
\text { a usar [...] é a dificuldade em ficar sem a droga." }\end{array}$ & $\begin{array}{l}\text { Prazer ilusório } \\
\text { e } \\
\text { momentâneo } \\
\text { proporcionado } \\
\text { pela droga. }\end{array}$ \\
\hline
\end{tabular}

Continuação na página seguinte. 


\begin{tabular}{|c|c|c|}
\hline \multicolumn{3}{|c|}{ Faculdade de Enfermagem UFPel } \\
\hline \multicolumn{3}{|c|}{ ontinuação da página anterior. } \\
\hline $\begin{array}{l}\text { E15, masculino, } 48 \text { anos, } \\
\text { estudou até } 8^{\mathrm{a}} \text { série, } \\
\text { usuário de álcool, } \\
\text { solteiro, um ano e meio } \\
\text { de tratamento no CAPS, } \\
\text { com inúmeras recaídas. }\end{array}$ & $\begin{array}{l}\text { "Eu tenho recaído porque não controlo minha } \\
\text { vontade, a vontade já está me pegando, me } \\
\text { infernizando, eu sonho bebendo. A vontade é mais } \\
\text { forte, não penso em nada, em ninguém, nem mesmo } \\
\text { em mim." }\end{array}$ & $\begin{array}{l}\text { Impulsividade } \\
\text { desencadeada } \\
\text { pela } \\
\text { abstinência. } \\
\text { Fissura no } \\
\text { tratamento }\end{array}$ \\
\hline $\begin{array}{l}\text { E2, masculino, } 29 \text { anos, } \\
\text { segundo grau incompleto, } \\
\text { usuário de crack, solteiro, } \\
\text { em tratamento há quatro } \\
\text { anos, com inúmeras } \\
\text { recaídas. }\end{array}$ & $\begin{array}{l}\text { "Eu sempre tenho recaído quando tem alguma coisa } \\
\text { que me frustro, eu não sei aceitar o não e por isso } \\
\text { tento preencher aquele vazio que ficou aquela raiva } \\
\text { usando a droga." }\end{array}$ & $\begin{array}{l}\text { Dificuldade } \\
\text { com as } \\
\text { frustrações }\end{array}$ \\
\hline $\begin{array}{l}\text { E12, feminino, } 27 \text { anos, } \\
\text { ensino fundamental } \\
\text { incompleto, } \\
\text { desempregada, usuária } \\
\text { de crack, casada, há três } \\
\text { anos em tratamento no } \\
\text { CAPS, contando com } \\
\text { inúmeras recaídas. }\end{array}$ & $\begin{array}{l}\text { "Tem manhã que eu amanheço muito irritada, aí eu } \\
\text { sei que é porque está fazendo falta a droga, o corpo } \\
\text { pede e nesse dia eu acabo cedendo ao corpo e volto a } \\
\text { usar a droga." }\end{array}$ & $\begin{array}{l}\text { Dependência } \\
\text { orgânica }\end{array}$ \\
\hline $\begin{array}{l}\text { E4, masculino, segundo } \\
\text { grau completo, } \\
\text { desempregado, } \\
\text { atualmente utiliza álcool } \\
\text { e já usou maconha, } \\
\text { cocaína e crack, um ano } \\
\text { em tratamento no CAPS, } \\
\text { com três recaídas. }\end{array}$ & $\begin{array}{l}\text { "Eu estou matando um leão por dia para tentar não } \\
\text { recair mais }[\ldots . .] \text {, só que é muito difícil [...] o } \\
\text { pensamento da droga toma conta de você, parece um } \\
\text { chip conectado no seu cérebro. E por mais que você } \\
\text { tome medicamentos a vontade da droga continua e } \\
\text { você volta a usar porque é uma coisa que está no seu } \\
\text { corpo, é uma química que está no seu sangue, corre } \\
\text { na veia e por essa vontade que toma conta de mim eu } \\
\text { acabo recaindo." }\end{array}$ & $\begin{array}{l}\text { Dominação da } \\
\text { droga }\end{array}$ \\
\hline $\begin{array}{l}\text { E6, masculino, } 66 \text { anos, } \\
\text { estudou até a sétima } \\
\text { série, trabalhou de } \\
\text { sapateiro e serviços } \\
\text { gerais, usuário de álcool, } \\
\text { solteiro, em tratamento } \\
\text { há um ano, totalizando } 2 \\
\text { recaídas. }\end{array}$ & $\begin{array}{l}\text { "Sempre que fico ansioso fico lembrando do prazer } \\
\text { que o álcool oferece, o sabor, a sensação de alegria, } \\
\text { daí quando estou meio para baixo eu lembro de tudo } \\
\text { isso e volto a beber." }\end{array}$ & $\begin{array}{l}\text { Fantasia rom } \\
\text { o vício e } \\
\text { ênfase nas } \\
\text { sensações } \\
\text { positivas } \\
\text { trazidas pelo } \\
\text { uso do álcool. }\end{array}$ \\
\hline
\end{tabular}

\section{DISCUSSÃO}

Segundo a primeira categoria os determinantes interpessoais são influências marcadas pelo contexto a qual indivíduo está inserido, seja em seu âmbito familiar, afetivo ou social. Sendo assim, o vínculo pode existir em relações mais sólidas como amizade, companheirismo, apoio e afeto, ou relações conflituosas como brigas e cobranças excessivas, podendo estes também emergem como determinantes de sentimentos negativos, aumentando a probabilidade para recaídas quanto ao uso de drogas. ${ }^{12}$

Os entrevistados afirmaram que as causas de suas recaídas estão 


\section{JOURNALOF \\ NURSING \\ ANO HEALTH}

ISSN 2236 - 1987

conhecidos que também utilizam substâncias psicoativas, e a presença constante em bares e festas onde há maior facilidade para aquisição de substâncias; um relacionado a finalidade do indivíduo tornar-se aceito no meio inserido e na intenção de mudança da extroversão, o outro, a maior frequência em bares e festas disponibiliza o encontro repentino e "acidental" com relativos influentes, sendo suscetível a recaídas.

É relevante notar que as associações da pressão social com a presença de bares e festas potencializam a possibilidade do reuso, porém, quando não há incentivo do uso, mesmo na frequência de lugares que facilitam a aquisição e contato próximo com a droga, a vontade própria do indivíduo de prosseguir e fortalecer o tratamento funciona como mecanismos para impedir a sua quebra. Como determinantes interpessoais, estes estariam mais relacionados a motivos de recaída. ${ }^{5}$

No caso de o dependente químico possuir moradia fixa e uma maior estrutura familiar, o ambiente não deve proporcionar uma ocasião para a recaída, devendo-se assim atentar ao círculo social do qual está inserido, uma vez que há a quebra do vínculo familiar e o livre acesso de pessoas que disponibilizem a droga ou influenciem o uso, no qual compromete o tratamento e o torna suscetível à recaída.

$\mathrm{Na}$ sociedade brasileira a bebida alcóolica é uma substância psicoativa socialmente aceita e está presente em grande parte das confraternizações familiares, no entanto, quando dentro desta família há um indivíduo 


\section{JOURNALOF \\ NURSING \\ AND HEALTH}

ISSN 2236 - 1987

sendo tal convívio muitas vezes conflituoso, uma vez que a família não se encontra preparada para enfrentar e entender as subjetividades de um indivíduo dependente de substâncias psicoativas. ${ }^{15}$

Brigas e conflitos familiares e frustrações também foram descritos como fortes motivos para o reuso das substâncias psicoativas, mesmo que os indivíduos não saibam, eles tornam-se vulneráveis à recaída quando algo se encontra em desequilíbrio em suas relações ou quando não possuem resiliência, a qual pode ser definida como um fenómeno que indica resultados relativamente bons de alguns indivíduos, apesar da experiência de vários riscos ou de adversidades durante a vida; deste modo, quanto menor a resiliência do indivíduo, maiores são as chances deste sofrer uma recaída.

Os conflitos interpessoais aparecem como um motivo para a continuidade do abuso de substâncias, visto que $o$ indivíduo em tratamento necessita de um apoio social, no entanto os conflitos e as relações conturbadas, sejam com familiares ou amigos, fazem com que ele tente fugir de sua realidade. Neste sentido, a participação do apoio social de caráter positivo e especializado (CAPS) pode contribuir no reconhecimento da dependência e vontade de superação, o trabalho em conjunto proporciona ao indivíduo o controle do uso, a permanência na abstinência e auxilia na prevenção da recaída. ${ }^{12}$

A situação empregatícia é outro aspecto relevante apontado como motivo de recaída, devido à sensação de frustação pela ausência do 


\section{JOURNALOF \\ NURSING \\ M०HEALTH}

ISSN $2236-1987$

emprego.

Historicamente,

dependentes químicos apresentam altos índices de desemprego e grandes dificuldades para conseguir trabalho, durante ou após o período de tratamento, isto ocorre por conta diversos fatores, que envolvam a deficiência na formação dos usuários, a relutância dos empregadores para contratar pessoas com histórico de dependência química, ou mesmo a falta de estímulo ao trabalho que pode decorrer da aquisição de benefícios sociais vinculados à doença e ao desemprego. ${ }^{16}$

Assim como vários outros fatores, os determinantes interpessoais são descritos pelos entrevistados como forte motivo para recaídas, visto que estes indivíduos apresentam dificuldades em enfrentar seus conflitos cotidianos. Neste sentido, estratégias como terapia cognitiva comportamental, terapia ocupacional, grupos de autoajuda, suporte religioso, alfabetização, capacitação e reinserção ao mercado de trabalho, prática de atividades físicas e alimentação saudável são algumas alternativas que devem ser criadas entre os serviços de saúde como o CAPS junto ao paciente e sua família, visando favorecer o relacionamento entre estes, criando assim um mecanismo de proteção às recaídas.

\section{Determinantes intrapessoais percebidos pelos dependentes químicos como causa de suas recaídas}

Determinantes intrapessoais, são determinantes que se correlacionam com os estados emocionais do indivíduo, tais como enfrentamento, motivação, auto eficácia, expectativas de resultados e a fissura. A expectativa de resultados ocorre quando 0 indivíduo antecipa os efeitos que espera obter em consequência do uso das substâncias, podendo ser de caráter físico, psicológico ou comportamental e ainda de cunho positivo ou negativo. A auto eficácia é caracterizada como o grau de confiança que a pessoa possui em relação a sua própria capacidade de realizar certo comportamento em um contexto específico.

0 enfrentamento é definido como a capacidade que o ser humano tem de usar estratégias efetivas para lidar com alguma situação de risco, tendo como objetivo reduzir do risco ou conseguir gratificação em dada situação. A motivação pode ser consciente ou inconsciente e é definida como estímulo para uma dada ação ou objeto. A fissura não é indicativa de recaída, é um fenômeno complexo descrito como um impulso forte para o uso da substância, desencadeado por sensações negativas. Estados emocionais também estão relacionados com a recaída, o afeto negativo reforça o consumo e o afeto positivo reforça a manutenção da abstinência. ${ }^{9}$ É necessário ressaltar que tanto os determinantes interpessoais quanto os intrapessoais, por vezes, associam-se uns com os outros no contexto do processo de recaída de dependentes químicos. ${ }^{17}$

$\mathrm{Na}$ respectiva categoria serão abordados aspectos relacionados a características intrapessoais dos sujeitos da pesquisa, das quais prejudicam a manutenção da abstinência e por consequência 
aparecem como motivos de recaída que devem ser considerados no plano terapêutico singular destes indivíduos. Seis entrevistados relataram que dentre os principais motivos que os levam a recaída estão à vontade física e psíquica, a fissura, a busca impensada pelo prazer momentâneo, os sintomas de abstinência e a dominação da droga sobre o dependente.

No relato do entrevistado dois (Figura 2), o mesmo se responsabiliza por ter recaído, mas pode-se inferir que a sua recaída aconteceu pela sensação de prazer que a droga proporciona a esse indivíduo. Neste caso, o tratamento deve abarcar aspectos que possam abarcar a compreensão desse prazer ilusório e momentâneo podendo diminuir 0 sofrimento destas pessoas e até mesmo ajudá-las a compreender essa vontade, como algo que deverá ser enfrentado por toda a sua vida.

Um dos determinantes intrapessoais para continuidade do abuso de substâncias psicoativas é a fissura, sendo um implacável adversário na recuperação e persistência no tratamento. A descrição de fissura pode demonstrarse como uma aspiração subjetiva de reprisar a vivência dos produtos resultantes da substância; esta aspiração é capaz de incidir na fase do próprio uso, na abstinência ou no intervalo prolongado sem 0 uso, acompanhado ou não de alterações no humor, pensamentos e comportamento. Esta sensação deixa o dependente químico vulnerável à recaídas, tendo como consequência o abandono do tratamento, mesmo quando este encontra-se disposto a manter-se em abstinência, porém 0 termo fissura não será relacionada ao tipo de droga, pois não contempla o objetivo do trabalho. ${ }^{9}$

0 entrevistado 15 (Figura 2) reconhece que é incapaz de controlar sua vontade, uma vez que relata reviver a necessidade da bebida de forma inconsciente, por meio do sonho. Também é perceptível na fala a impulsividade desencadeada pela abstinência, constituindo um ponto de fissura no tratamento, que compromete sua relação social e o próprio bem-estar.

Por vezes as drogas são utilizadas pelos usuários para preencher "os seus vazios", uma vez que a substância psicoativa possui a capacidade mascarar a fragilidade encontrada nos dependentes químicos para 0 enfrentamento de problemas/conflitos, tornando-os susceptíveis às recaídas, uma vez que as drogas podem servir como alívio aos seus sentimentos indesejáveis.

As frustrações são situações inerentes do viver humano, o que as faz aparecer como um motivo de recaída para o abuso de drogas é a pouca capacidade de enfrentamento de conflito. A literatura aponta que os estados emocionais como raiva e sensação de vazio são os motivos mais citados para a continuidade da dependência de substâncias psicoativas. ${ }^{9}$

No depoimento do entrevistado doze (Figura 2) trata-se da dependência orgânica causada pela droga e os efeitos físicos e psicológicos de interrupção do uso. Neste contexto, 


\section{JOURNAIOF

verifica-se a luta enfrentada pela usuária, uma vez que esta não supera a falta da substância, sendo a irritação e ansiedade fatores que favorecem a recaída.

0 período de abstinência é uma fase crítica do tratamento, onde se manifestam incialmente ansiedade, irritação, depressão que evoluem para tremores, suor, taquicardia, náuseas e vômito. Nessa fase, portanto, cabe atenção redobrada da equipe multidisciplinar responsável pelo tratamento, a fim de que a dificuldade dos pacientes seja a menor possível. ${ }^{18}$

Observa-se que a droga tem dominação sobre o paciente e que o uso de medicamentos, apesar de auxiliar na continuidade do tratamento, não é capaz de impedir a recaída. 0 entrevistado tem ainda consciência a respeito da dominação química que a substância tem sobre o organismo como predisposição à fissura e consequente recaída.

A dominação da droga leva a perturbação do psicológico do usuário, ou seja, o indivíduo se encontra numa situação desenfreada do uso da droga para produzir prazer ou um bem-estar. Esta dependência psíquica indica a existência de alterações da personalidade que acabam conduzindo ao uso como forma de manter o hábito. Somados os fatores como sintomas de abstinência, o hábito e a alteração de personalidade causada pela droga há uma combinação que predispõe à recaída. ${ }^{19}$

No relato do entrevistado seis (Figura 2) a fantasia com o vício e ênfase nas sensações positivas trazidas pelo uso do álcool aparecem como fatores preditivos para o retorno a sensações agradáveis. A ansiedade e situações de tristeza são colocadas como fatores desencadeantes da recaída, numa tentativa de sentir felicidade novamente.

Os pacientes que relatam determinantes intrapessoais como causas principais para a recaída no tratamento descrevem uma necessidade incontrolável da droga como forma de sanar suas necessidades físicas e emocionais, muitas vezes desencadeadas por incapacidade de absorver frustrações, que pode ser descrita como necessidade orgânica e/ou psíquica, uma vez que durante o período de abstinência relatam sintomas físicos e psicológicos pela falta de uso dessas substâncias.

Dessa forma, o tratamento somático e psicossocial bem ajustado, no plano doméstico e ambulatorial, é necessário para orientar sobre as possíveis recaídas os fatores que a iniciam. Nesse caso, é necessário saber quais são as fontes de prazer do paciente fora da esfera drogas e orientá-lo a praticá-las, pois irão acionar o sistema de recompensa do cérebro, uma área encarregada de receber estímulos e transmitir essa sensação para o corpo todo. ${ }^{20}$

Os determinantes intrapessoais são apontados pelos entrevistados como fortes motivos para os levarem ao retorno das substâncias psicoativas, ocasionados pelo prazer ilusório e momentâneo que a mesma proporciona, além da fissura e dos efeitos físicos e psicológicos da abstinência. Normalmente, estes determinantes tornam-se fatores desencadeantes quando associados à 


\section{JOURNALOF \\ NURSING \\ ${ }^{\text {AND HEALTH }}$}

ISSN 2236 - 1987

ansiedade e situaçõos de tristeza, assim há a necessidade de favorecer o aumento da resiliência destes indivíduos, onde aprenderam a se adaptar às novas situações que surgirem em sua vida, evitando as recaídas.

\section{CONCLUSÃO}

Percebeu-se que os principais motivos que levam o indivíduo dependente químico a reiniciar o uso das substâncias psicoativas emergiram em duas categorias, sendo estas os determinantes interpessoais e intrapessoais. Os primeiros, encontrados a partir dos depoimentos dos participantes da pesquisa, os quais relataram que os conflitos cotidianos têm vínculo com suas relações sociais, com as frustrações vividas, com os locais dos quais se encontram inseridos e a proximidade com a droga. Já categorizados como determinantes intrapessoais estão listados a vontade física e psíquica, a fissura, a busca impensada pelo prazer momentâneo e os sintomas de abstinência, sendo todos estes caminhos responsáveis por levar o indivíduo à recaída.

Esta pesquisa expõe restrições ao ponderar 0 entendimento sobre dependentes químicos a um meio de conduta e de uma específica atmosfera, entretanto houve possibilidade de constatar relevantes fatores preditivos a episódios de recaída, devido aos dados obtidos. A experiência da recaída está integrada a múltiplos determinantes, que ocorrem simultaneamente, o que constitui uma dificuldade em considerar todos estes aspectos no processo de reabilitação e tratamento, visto que cada sujeito possui sua individualidade e diferentes capacidades de resiliência.

Almeja-se que os levantamentos de indagações sobre esta pesquisa sejam de grande valia e cooperem na caminhada da reabilitação dos usuários, devido a recaída estar inclusa no decorrer do processo de tratamento do dependente químico, os profissionais de saúde devem então ampliar seus conhecimentos sobre a dependência química em um modo geral, ressaltando a importância dos determinantes intrapessoais e interpessoais, para que possam assim ser utilizados como estratégia terapêutica. Salienta-se a necessidade de implementação das políticas públicas já existentes, que atuam com os dependentes de substâncias psicoativas focando-se em estratégias alternativas que visem manter 0 sujeito próximo de sua realidade, contando com o auxílio da Rede de Atenção Psicossocial (RAPS), estando a salvo as internações em casos de necessárias estabilizações e redução de danos ao indivíduo.

\section{REFERÊNCIAS}

1 American Psychiatric Association (APA). Manual diagnóstico e estatístico de transtornos mentais: DSM-5. $5^{\mathrm{a}}$ ed. Porto Alegre: Artmed; 2014. [acesso em 2018 set 02]. Disponível em: https: / /aempreendedora.com.br/wpcontent/uploads/2017/04/ManualDiagn\%C3\%B3stico-e-

Estat\%C3\%ADstico-de-TranstornosMentais-DSM-5.pdf

2 Ferreira ACZ, Czarnobay J, Borba LO, Capistrano FC, Kalinke LP, Maftum MA. Determinantes intra e interpessoais da 


\section{JOURNALOF \\ NURSING \\ ${ }^{\text {AND HEALTH }}$}

recaída de dependentes químicos. Rev eletronica enferm [Internet]. 2016 [acesso em 2018 set 24];18:e1144. Disponível

em:

http://dx.doi.org/10.5216/ree.v18.34 292

3 United Nations Office on Drugs and Crime (UNODC). World Drug Report 2017 [Internet]. 2017. [cited 2018 Sept 12]. Available from: https: / /www.unodc.org/wdr2017/fiel d/Booklet_1_EXSUM.pdf

4 Junior WAR, Souza RG, Cruz ERB, Leite AG, Almeida LM. Prevenção ao uso abusivo de drogas no ambiente escolar através do processo de sensibilização e conscientização. Carpe diem: revista cultural e científica do UNIFACEX [Internet]. 2016[acesso em 2018 out 13];14(1):31 $42 . \quad$ Disponível em: https://periodicos.unifacex.com.br/R evista/article/view/694/pdf

5 Silva ML, Guimarães CF, Salles DB. Fatores de risco e proteção à recaída na percepção de usuários de substâncias psicoativas. Rev rene [Internet]. 2014 [acesso em 2018 set 02];15(6):1007-15. Disponível em: http: / / www.redalyc.org/articulo.oa?i $\mathrm{d}=324041233014$.

6 Cafruni KH, Brolese G, Lopes F. Tratamentos Não Farmacológicos para Dependência Química. Diaphora: revista da sociedade de psicologia do Rio Grande do Sul [Internet]. 2014 [acesso em 2018 set 02];14(1):10-9. Disponível em: http://www.sprgs.org.br/diaphora/oj s/index.php/diaphora/article/view/3 $2 / 32$.

7 Sanches JFA, Almeida KPB, Magalhães JM. $O$ significado dos
ISSN $2236-1987$

usuários de álcool e outras drogas sobre recaídas. Revista interdisciplinar [Internet]. 2015 [acesso em 2018 set 02];8(2):53-9. Disponível em: https:// revistainterdisciplinar.uninova fapi.edu.br/index.php/revinter/articl e/view/503/pdf_211

8 Illán-López OC. Reflexiones metodológicas sobre la inmersión al campo con poblaciónen recaía en el consumo de drogas: un estudio preliminar. Rev esp drogodepend [Internet]. 2014 [acesso em 2018 set 02]; 39(3):80-93. Disponível em: https://dialnet.unirioja.es/servlet/ar ticulo? codigo $=5014448$ \& orden $=1$ \&info= link

9 Ferreira ACZ, Czarnobay J, Borba LO, Capistrano FC, Kalinke LP, Maftum MA. Determinantes intra e interpessoais da recaída de dependentes químicos. Rev eletronica enferm [Internet]. 2016 [acesso em 2018 set 02];19(2):93-9. Disponível em: https: / /www.revistas.ufg.br/fen/arti cle/download/34292/21002

10 Minayo, MCS. Análise qualitativa: teoria, passos e fidedignidade. Ciênc saúde colet. [Internet]. 2012 [acesso em 2018 set 02];17(3):621-6. Disponível em: http://www.scielo.br/pdf/csc/v17n3/ v17n3a07.pdf

11 Silva $A H$, Fossá MIT. Análise de conteúdo: exemplo de aplicação da técnica para análise de dados qualitativos. Qualitas revista eletrônica [Internet]. 2015 [acesso em 2018 set 02];17(1):1-14. Disponível em: http://revista.uepb.edu.br/index.php /qualitas/article/view/2113/

12 Almeida CS. Determinantes intrapessoais e interpessoais do 


\section{ISSN 2236 - 1987}

processo de recaída em usuários de crack [dissertação] [Internet]. Ribeirão Preto (SP): Universidade de São Paulo; 2015 [acesso em 2018 set 02]. Disponível em: http://www.teses.usp.br/teses/dispo niveis/22/22131/tde-04092015160809/pt-br.php

13 Ferreira ACZ, Borba LO, Capistrano FC, Czarnobay J, Maftum MA. Fatores que interferem na adesão ao tratamento de dependência química: percepção de profissionais de saúde. REME rev min enferm [Internet]. 2015[acesso em 2018 set 02];19(2):150-6. Disponível em: http://www.reme.org.br/artigo/detal hes $/ 1012$

14 Vasconcelos ACM, Araújo LM, Porto LGM, Rocha NNV, Oliveira EN, Albuquerque JTPJ. Relações familiares e dependência química: uma revisão de literatura. Rev bras ciênc saúde. [Internet]. 2015 [acesso em 2018 set 02]; 19(4):321-6. Disponível em: http://periodicos.ufpb.br/index.php/ rbcs/article/viewFile/24316/15109

15. Laranjeira R (organizador). II Levantamento Nacional de Álcool e Drogas - 2012 [Internet]. São Paulo: UNIFESP; 2014 [acesso em 2018 set 02]. Disponível

https: / /inpad.org.br/wp-

content/uploads/2014/03/Lenad-II-

Relat\%C3\%B3rio.pdf

16 Bonadio AN, Silveira C. Economia Solidária e Reabilitação Vocacional no campo da drogadição: possibilidades e limites das práticas atuais. Saúde e sociedade [Internet]. 2013 [acesso em 2018 set 02];22(1):99-108. Disponível em: http://www.scielo.br/pdf/sausoc/v22 $\mathrm{n} 1 / 10 . \mathrm{pdf}$

17 Almeida CS. Determinantes intrapessoais e interpessoais do processo de recaída em usuários de crack [dissertação] [Internet]. Ribeirão Preto (SP): Universidade de São Paulo; 2015 [acesso em 2018 set 25]. Disponível em: http: / /www.teses.usp.br/teses/dispo niveis/22/22131/tde-04092015160809/en.php

18 Henriques JAS, Hildebrandt LM, Leite MT, Van der Sand ICP. Cuidado a pessoas com dependência química em hospital geral na ótica da equipe de enfermagem. Rev enferm UFSM [Internet]. 2013 [acesso em 2018 set 02]; 3(3):383-93. Disponível em: http: //periodicos.ufsm.br/reufsm/art icle/view/7998

19 Gregório T. O Papel da Família no tratamento do usuário de drogas [monografia]. Criciúma (SC): Universidade do Extremo Sul Catarinense; 2013 [acesso em 2018 set 02]. Disponível em: http://repositorio.unesc.net/bitstrea $\mathrm{m} / 1 / 2152 / 1 /$ Tereza\%20Greg\%C3\%B3ri o.pdf

20 Maia FES. A devassidão que o crack traz. Revista da faculdade de ciências médicas de Sococaba [Internet]. 2015 [acesso em 2018 set 02];17(3):172-3. Disponível em: http://revistas.pucsp.br/index.php/R FCMS/article/view/19922/pdf

Data de submissão: $24 / 07 / 2018$

Data de aceite: $21 / 10 / 2018$

Data de publicação: 09/11/2018 